\title{
Hot working behavior of duplex stainless steel UNS $\$ 32750$ characterized by constitutive equations and processing maps
}

\author{
Xin $\mathrm{ZHAO}^{1, \text { a }}$, Langji $\mathrm{CHEN}^{1, \mathrm{~b}}$ \\ ${ }^{1}$ The Six Department, Zhengzhou University of Aeronautics Zhengzhou 450015, China \\ azhaoxin@zzia.edu.cn, bedward9@163.com
}

\begin{abstract}
The hot deformation characteristics of duplex stainless steel UNS S32750 were studied in the temperature range of $900-1200^{\circ} \mathrm{C}$ and strain rate range of $0.1-10 \mathrm{~s}^{-1}$ by using hot compression tests. Flow stress was modeled by the constitutive equation of hyperbolic sine function. Processing maps for hot working were developed. The results reveal that the flow curves are nearly typical of DRX and DRV at low and high deformation temperatures where austenite and ferrite are dominant, respectively. In the processing map under stain of 0.7 , a domain is centered at $1200{ }^{\circ} \mathrm{C}$ and $0.1 \mathrm{~s}^{-1}$, and the maximum efficiency is more than $36 \%$. According to the maps, the zone with the temperature range of $1100-1200^{\circ} \mathrm{C}$ and strain rate range of $0.1-1 \mathrm{~s}^{-1}$ may be considered as the optimum region for hot working.
\end{abstract}

\section{Introduction}

Over the past few decades, duplex stainless steels (DSS) have aroused considerable interest in metallurgical engineers because of their better corrosion resistance and higher strength [1-2]. They are considered as excellent choices for various industrial applications. However, the coexistence of ferrite and austenite in the structure of DSS has made the hot deformation very controversial. Because ferrite is characterized by high stacking fault energy (SFE) and therefore undergoes dynamic recovery (DRV) [4]. On the contrary, austenite, having a low SFE, undergoes only limited DRV. As a result, when the dislocation density reaches a critical value, dynamic recrystallization (DRX) comes into operation [4]. The dissimilar plastic behavior and restoration mechanism of austenite and ferrite during the hot deformation may lead to a drastic decrease in the hot ductility [5]. Thus, the development of processing maps, defining a "safe" window in the temperature-strain rate field is of great significance for DSS. Processing maps are developed on the basis of the dynamic material model [6]. The principles of this approach and its applications to the hot deformation of a wide range of materials have been described by many researchers. The present work is devoted to study the high-temperature deformation behavior of a duplex stainless steel UNS S32750 by using the analysis of flow curves, constitutive equations and processing maps.

* Corresponding author:zhaoxin@zzia.edu.cn 


\section{Experimental procedure}

The material used in this study was the duplex stainless steel UNS S32750 having the composition of $0.019 \% \mathrm{C}, 0.43 \% \mathrm{Si}, 0.95 \% \mathrm{Mn}, 0.005 \% \mathrm{~S}, 0.025 \% \mathrm{P}, 25.38 \% \mathrm{Cr}, 6.97 \% \mathrm{Ni}$, $3.86 \% \mathrm{Mo}, 0.28 \% \mathrm{~N}$ and the rest of $\mathrm{Fe}$ (all in wt. \%). The starting microstructure consisted of about $45 \%$ ferrite and $54 \%$ austenite. The cylinder upsetting specimens with the gauge dimension of $6 \mathrm{~mm}$ in diameter and $10 \mathrm{~mm}$ in length were machined from the as-cast plates. Hot compression tests at constant strain rate were carried out over a temperature range varying from $900^{\circ} \mathrm{C}$ to $1200^{\circ} \mathrm{C}$ and at different true strain rates ranging from 0.1 to $10 \mathrm{~s}^{-1}$ by using a Gleeble dynamic material testing machine. Each specimen was heated up to the test temperature at an average rate of $5^{\circ} \mathrm{C} / \mathrm{s}$ and kept for 180 seconds, and then deformed to a true strain of 0.7 .Then, specimens were immediately water cooled to room temperature following deformation. Hot deformed specimens were cut along the longitudinal axis and the cut surfaces were prepared for metallographic examination. Microstructural changes through hot deformation were observed by using an optical microscopy.

\section{Results and discussion}

\subsection{Stress-strain curves}

The true stress-true strain curves of the duplex stainless steel UNS S32750 under different temperatures and strain rates are shown in Fig. 1. The different features of flow curves can be interpreted considering the coexistence of different constitutions, i.e. ferrite and austenite. In details, at high temperatures as shown in Fig. 1(a), flow curves are nearly typical of DRV where ferrite is the dominant phase in the microstructure [2]. On the contrary, at low deformation temperatures as shown in Fig. 1(d), the increase in the austenite volume fraction [2] turns the apparent aspect of flow curves to that of DRX characterized by the appearance of a peak followed by flow softening. At mediate high temperatures, the work softening isn't very remarkable and the curves increase up to the peak followed by a moderate decrease in true stress. This suggests that DRV may take place in the ferrite region and DRX in the austenite region at the same time.
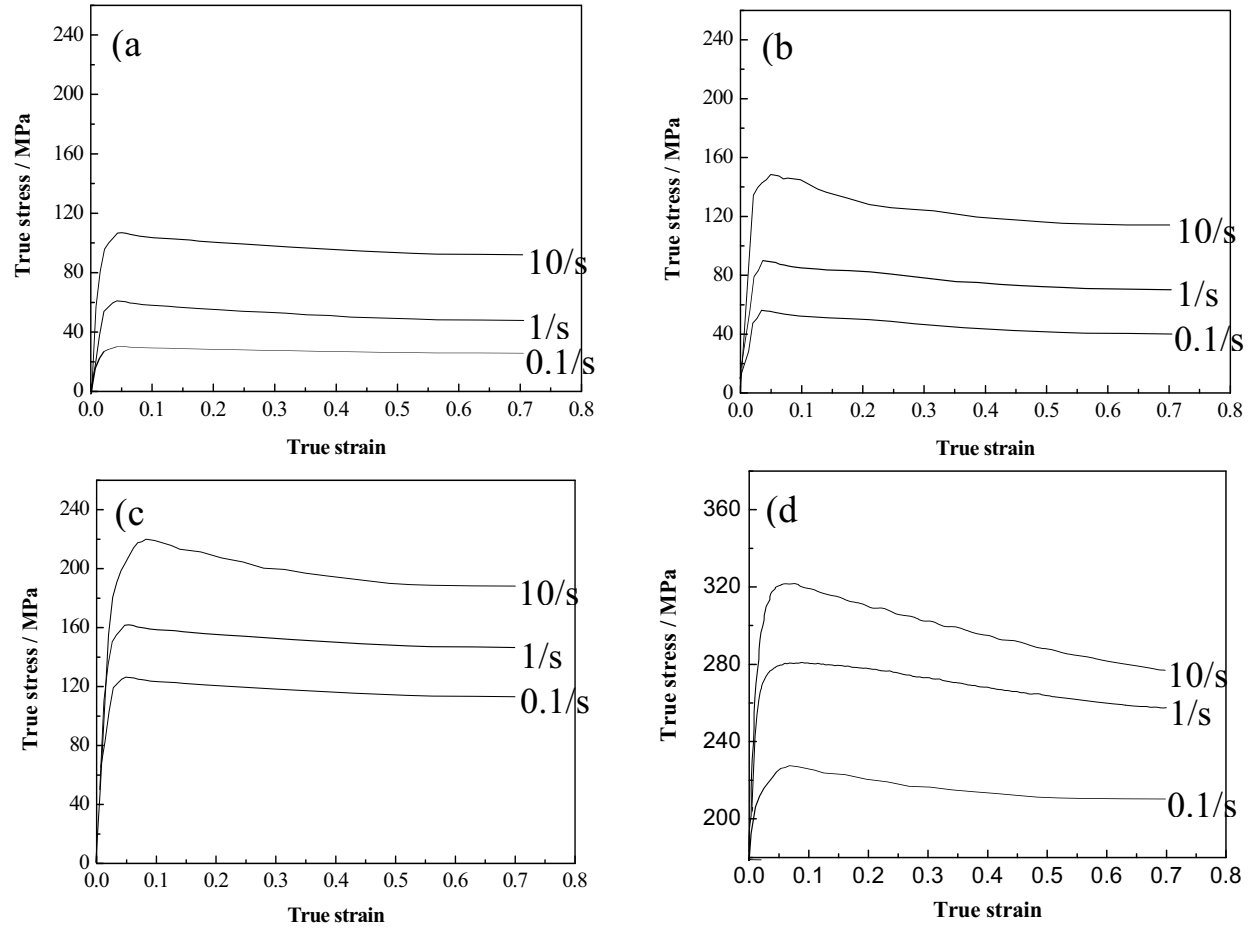

Fig. 1 True stress-strain curves of $\mathrm{S} 32750$ steel deformed at various temperatures
(a) $1200^{\circ} \mathrm{C}$
(b) $1100^{\circ} \mathrm{C}$
(c) $1000^{\circ} \mathrm{C}$
(d) $900^{\circ} \mathrm{C}$ 


\subsection{Constitutive analysis}

The dependence of flow stress to hot deformation variables can be analyzed by the well-known hyperbolic sine function incorporated with the definition of the Zener-Hollomon parameter as follows:

$$
Z=A[\sinh (\alpha \sigma)]^{n}=\stackrel{\&}{\varepsilon} \exp (Q / R T)
$$

where $\mathrm{Z}$ is the Zener-Hollomon parameter embracing the effects of strain rate and temperature, $\sigma$ is the flow stress, $\stackrel{\&}{\mathcal{E}}$ is strain rate, $Q$ is the activation energy, $T$ is the absolute temperature, $\mathrm{R}$ is the universal gas constant and $\mathrm{A}, \alpha$ and $\mathrm{n}$ are material constants. The Eq. (1) has shown good agreement with many experimental data within wide strain rate and temperature ranges.

Partial differentiation of Eq. (1) gives:

$$
Q=R \bullet\left[\frac{\partial \ln \varepsilon}{\partial\left(\ln \sinh \left(\alpha \sigma_{p}\right)\right)}\right]_{T} \bullet\left[\frac{\partial \ln \sigma_{p}}{\partial(1 / T)}\right]_{\varepsilon}
$$

$\&$

where the last two terms of Eq. (2) represent the slope of the $\ln \stackrel{\&}{\varepsilon}$ vs $\ln \left[\sinh \left(\alpha \sigma_{\mathrm{P}}\right)\right]$ plot at the temperatures employed and the slope of $\ln \left[\sinh \left(\alpha \sigma_{\mathrm{P}}\right)\right]$ vs $(1 / T)$ at the strain rates of interest, respectively.

Fig. 2 shows the variation of $\ln \stackrel{\&}{\varepsilon}$ with $\ln \left[\sinh \left(\alpha \sigma_{\mathrm{P}}\right)\right]$ meets the line relation who illustrates the relation of strain rate and stress of UNS S32750 stainless steel meets the formation of hyperbolic sine. Fig. 3 shows the variation of $10000 / T$ with $\ln \left[\sinh \left(\alpha \sigma_{\mathrm{P}}\right)\right.$ ] meets the line relation as well. By applying linear regression, the averages of slops in Fig 2 and 3 can be calculated, respectively. And then the amount of the apparent activation energy Q was determined as $496 \mathrm{~kJ} / \mathrm{mol}$. This value likes the apparent activation energy of austenite, which is significantly higher than that of ferrite [7]. It also suggests that DRX may take place in the austenite region under all conditions of this study.

The material constants were calculated according to the method in reference [8]. By replacing the values obtained for the material constants, the constitutive function for the studied steel was developed as follows:

$$
\stackrel{\&}{\varepsilon}=8.3 \times 10^{18}\left[\sinh \left(0.0086 \sigma_{\mathrm{p}}\right)\right]^{4.2} \exp (-496400 / \mathrm{RT})
$$




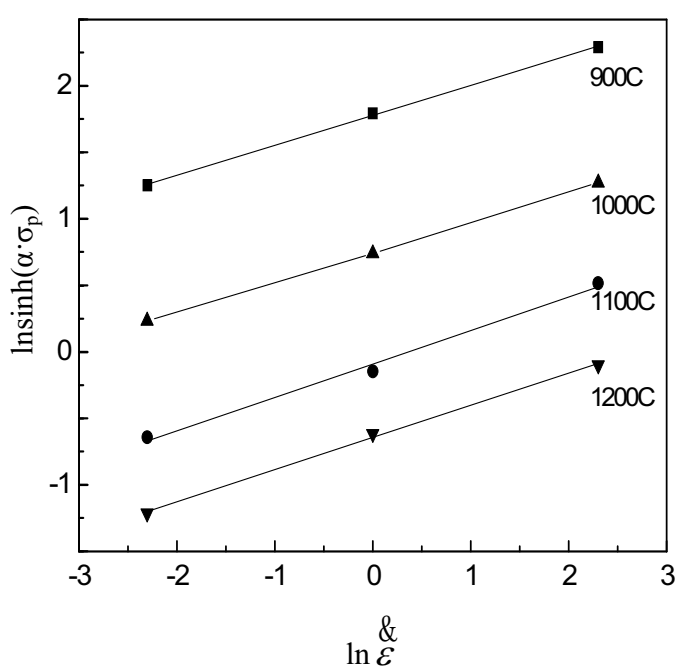

Fig.2 The alternation of flow stresses with strain rate

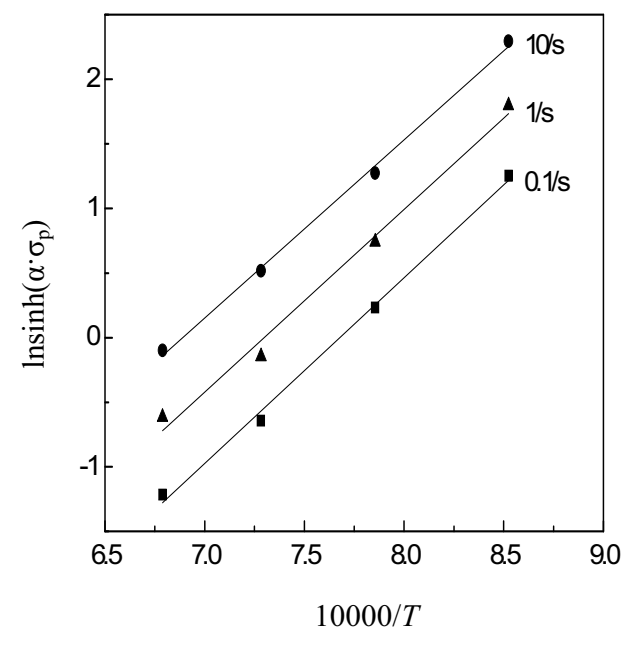

Fig.3 The alternation of flow stresses with temperature

\subsection{Characterization of processing maps}

Processing maps are developed on the basis of the dynamic material model [6]. The power dissipation characteristics of the workpiece depend upon the constitutive flow behavior of the material, which follows a power law equation:

$$
\sigma=k \stackrel{\&}{\varepsilon}^{m}
$$

where $\sigma$ is the flow stress, $\stackrel{\&}{\mathcal{E}}$ is the strain rate, $m$ is strain rate sensitivity and $\mathrm{k}$ is a constant. The $\log \sigma$ versus $\log \stackrel{\&}{\varepsilon}$ data are fitted using a cubic spline, and the strain rate sensitivity $m$ is calculated as a function of strain rate. The model considers the work piece as a dissipater of power system and that the instantaneous power dissipated at a given strain rate

$(\stackrel{\&}{\varepsilon})$ consists of two complementary parts: the G content and the J co-content, representing the temperature rise and the microstructural dissipation, respectively. The factor that partitions the power between $\mathrm{J}$ and $\mathrm{G}$ is the strain rate sensitivity $(m)$ of the flow stress $(\sigma)$, and the $\mathrm{J}$ co-content being given by:

$$
J=\frac{m}{m+1} \sigma \varepsilon \&
$$

where $\stackrel{\&}{\varepsilon}$ is the strain rate. For an ideal linear dissipater, $J=J_{\max }=(\sigma \stackrel{\&}{\mathcal{E}}) / 2$. For a non-linear dissipater, the efficiency of power dissipation may be expressed in terms of a dimensionless parameter:

$$
\eta=\frac{J}{J_{\max }}=\frac{2 m}{m+1}
$$

The variation of $\eta$ with temperature and strain rate constitutes the power dissipation map. The power dissipation maps are continuum maps and are interpreted in terms of the 
microstructural processes. With the help of an instability map developed by using the continuum instability criterion [9] given by:

$$
\xi \stackrel{\&}{\varepsilon}=\frac{m+}{\underset{\varepsilon}{\&}}+m<.
$$

Flow instabilities are predicted to occur when the dimensionless instability parameter $\xi$ becomes negative. Then, it is possible to arrive at the optimum parameters for designing a metalworking process without resorting to expensive and time-consuming trial and error methods.

The processing maps obtained at strains of $0.1,0.3,0.5$ and 0.7 are shown in Fig. 4 . In this figure, the counter numbers represent the efficiency of power dissipation and the shaded region where the dimensionless instability parameter $\xi$ is negative corresponds to flow instability.
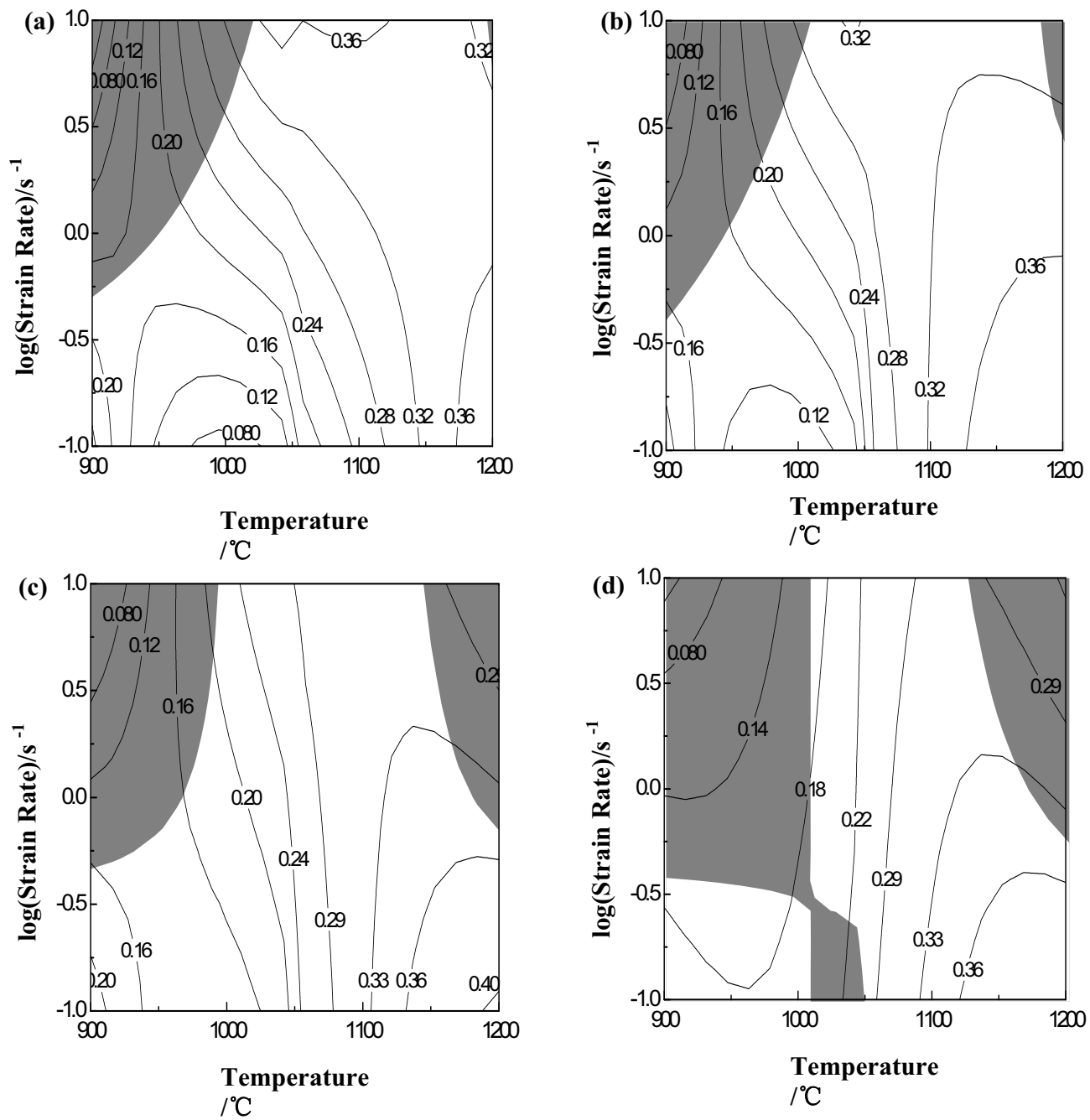

Fig. 4 Processing maps of S32750 steel deformed at various strains: (a)0.1, (b)0.3, (c)0.5, (d) 0.7

Contour numbers represent percent efficiency of power dissipation. Shaded regions correspond to flow instability. 
The map at strain of 0.1 exhibits two domains as shown in Fig 4 (a). The first domain is at $1200^{\circ} \mathrm{C}$ and $0.1 \mathrm{~s}^{-1}$, and its peak efficiency is more than $36 \%$. The second one is at $1050^{\circ} \mathrm{C}$ and $10 \mathrm{~s}^{-1}$ with peak efficiency more than $36 \%$. When the strain is more than 0.3 , the second domain disappears. When the strain increases up to 0.7 , the first domain keeps at $1200^{\circ} \mathrm{C}$ and $0.1 \mathrm{~s}^{-1}$, as shown in Fig 4 (d). The maximum efficiency is more than $36 \%$. This domain is a "safe" window for hot working of the tested material. Thus, the region with the temperature range of $1100-1200^{\circ} \mathrm{C}$ and strain rate range of $0.1-1 \mathrm{~s}^{-1}$ should be selected for hot working of UNS S32750 steel.

\section{Conclusions}

(1) The flow curves are nearly typical of DRX and DRV at low and high deformation temperatures where austenite and ferrite are dominant, respectively.

(2) The flow stress is very well fitted by the constitutive equation of hyperbolic sine function. The constitutive function is developed as $\stackrel{\&}{\varepsilon}=8.3 \times 10^{18}\left[\sinh \left(0.0086 \sigma_{\mathrm{p}}\right)\right]^{4.2} \exp (-496400 / \mathrm{RT})$.

(3) In the processing map at stain of 0.7 , a domain is centered at $1200^{\circ} \mathrm{C}$ and $0.1 \mathrm{~s}^{-1}$, and the maximum efficiency is more than $36 \%$. According to the maps, the zone with the temperature range of $1100-1200^{\circ} \mathrm{C}$ and strain rate range of $0.1-1 \mathrm{~s}^{-1}$ may be considered as the optimum region for hot working.

\section{References}

1. S.S.M. Tavares, V.G. Silva, J.M. Pardal, J.S. Corte. Investigation of stress corrosion cracks in a UNS S32750 superduplex stainless steel [J]. Engineering Failure Analysis. 2013, 35: 88-94

2. S. Huang, Z.G. Song, W.J. Zheng, et al. Influence of solution temperature on microstructure and mechanical properties of $00 \mathrm{Cr} 27 \mathrm{Ni} 7 \mathrm{Mo} 5 \mathrm{~N}$ [J]. Iron and Steel, 2011, 46(12): 71-76 (in Chinese)

3. A. Momeni, K. Dehghani, M.C. Poletti. Law of mixture used to model the flow behavior of a duplex stainless steel at high temperatures [J]. Mater. Chem. Phys. 2013, 139(2-3): 747-755

4. P. Mao, K. Yang, G. Su. Hot Deformation Behavior of an As-cast Duplex Stainless Steel [J]. J. Mater. Sci. Technol. 2003, 19(04): 379-381.

5. A. Iza-Mendia, A. Pinol-Juez, J.J. Urcola, et a1. Microstructural and mechanical behavior of a duplex stainless steel under hot working conditions [J]. Metall. Mater. Trans. 1998, 29A: 2975-2986.

6. Rishi Raj. Development of a Processing Map for Use in Warm-Forming and Hot-Formign Processing [J]. Metall. Trans. 1981, 12A: 1089-1098

7. L. Duprez, B.C.De Cooman, N. Akdut. Flow Stress and Ductility of Duplex Stainless Steel during High-Temperature Torsion Deformation [J]. Metall. Mater. Trans. 2002, 33A (7): 1931-1938

8. X. Zhao. Material Constants of Ferritic Spheroidal Cast Iron during Hot Deformation [J]. Mater. Sci. Forum. 2008, 575-578: 164-168

9. Y.V.R.K. Prasad, S. Sasidhara (Eds.): Hot Working Guide: A Compendium of Processing Maps, ASM International, Materials Park, OH, 1997 